This article has been accepted for publication in a future issue of this journal, but has not been fully edited.

Content may change prior to final publication in an issue of the journal. To cite the paper please use the doi provided on the Digital Library page.

\title{
Challenges, Advances and Future Directions in Protection of Hybrid AC/DC Microgrids
}

\author{
${ }^{\mathrm{a}}$ Sohrab Mirsaeidi, ${ }^{\mathrm{a}}$ Xinzhou Dong, ${ }^{\mathrm{a}}$ Shenxing Shi, and ${ }^{\mathrm{b}}$ Dimitrios Tzelepis \\ ${ }^{a}$ Department of Electrical Engineering, Tsinghua University, Beijing, P. R. China \\ ${ }^{\mathrm{b}}$ Department of Electronic and Electrical Engineering, University of Strathclyde, Glasgow, U. K. \\ *Corresponding author, email address: m_sohrab@mail.tsinghua.edu.cn
}

\begin{abstract}
Hybrid microgrids which consist of AC and DC subgrids interconnected by power electronic interfaces have attracted much attention in recent years. They not only can integrate the main benefits of both $\mathrm{AC}$ and DC configurations, but also can reduce the number of converters in connection of Distributed Generation (DG) sources, Energy Storage Systems (ESSs) and loads to AC or DC buses. In this paper, the structure of hybrid microgrids is discussed, and then a broad overview of the available protection devices and approaches for AC and DC subgrids is presented. After description, analysis and classification of the existing schemes, some research directions including communication infrastructures, combined control and protection schemes, and promising devices for the realisation of future hybrid AC/DC microgrids are pointed out.
\end{abstract}

Keywords: Hybrid AC/DC microgrids, AC subgrids, DC subgrids, protection challenges, protection schemes.

\section{Introduction}

Three phase AC-based power systems have existed for over one century due to easy transformation at different voltage levels and over long distances. In recent years, due to the environmental concerns raised by coal or gas driven generators, low voltage distribution systems (which operate as distributed generations or as $\mathrm{AC}$ microgrids) have attracted much attention [1]. In these systems, DG sources are connected to local AC main grid to supply local loads, which reduce the stress on transmission systems [2], [3]. In an AC microgrid, DG sources with DC output power are connected to the buses indirectly through DC/AC converters [4], [5]. DC microgrids have also been proposed in [6] to reduce the conversion from DC to AC. However, AC power in a DC grid has to be converted into DC and AC loads are connected into DC grid using DC/AC converters. Hence, the efficiency is considerably reduced because of multistage reverse conversions in an AC or a DC microgrid $[7]$.

The concept of hybrid AC/DC microgrid is proposed in [8] which combines the advantages of AC and DC 
This article has been accepted for publication in a future issue of this journal, but has not been fully edited.

Content may change prior to final publication in an issue of the journal. To cite the paper please use the doi provided on the Digital Library page.

architectures. The main feature of hybrid AC/DC microgrid is that its AC and DC subgrids are combined in the same distribution grid, facilitating the direct integration of both AC- and DC-based DG sources, ESSs and loads. This feature provides an efficient way for the integration of upcoming Renewable Energy Sources (RES) or Electric Vehicle (EV) units with minimum modifications of the current distribution grid, reducing the total cost.

In spite of many benefits provided by microgrids, there are some technical challenges which need to be resolved to accelerate their practical feasibility. One field which requires more attention is the protection. A significant challenge associated with the protection of microgrid is that the magnitude of short-circuit currents in islanded mode of operation is too low [9]. The reason is that the power electronic interfaces required for the connection of DG sources to the microgrid are designed to limit their output current to protect their semiconductor switches [10]. Hence, fault detection strategies for the islanded operating mode should be based on low short-circuit currents. In fact, a desirable microgrid protection scheme should not only possess the general features such as sensitivity, selectivity, speed of response and security level, but also ponder the number of installed DG sources and the fault current contribution of each of them in the islanded operating mode [11]. In recent years, many studies have been conducted to design and model effective protection strategies for microgrids. In this paper, the pivotal challenges in protection of hybrid AC/DC microgrids are discussed, and the existing methodologies against these challenges are further analysed and classified.

The remainder of this paper is as follows: Section 2 introduces the structure of hybrid AC/DC microgrids. In Section 3, the key issues and challenges in protection of microgrids are discussed. Section 4 highlights the most recent works performed on the microgrid protection. In Section 5, some research directions for protection of future hybrid AC/DC microgrids are suggested. Finally, Section 6 presents the main conclusions derived from this survey.

\section{Hybrid AC/DC microgrids}

To date, AC-based power systems have been the most popular architecture which is used for the majority of microgrid research projects. Since the design and modeling of AC systems is much simpler than DC ones, a large number of microgrids around the world have been developed based on this technology [12], [13]. The economic and technical challenges associated with the operation of AC systems have led academic researchers and power system engineers to conduct research on the feasibility of DC energy systems. The results of the researches have indicated that DC systems not only can enhance the efficiency of the network by decreasing the 
This article has been accepted for publication in a future issue of this journal, but has not been fully edited.

Content may change prior to final publication in an issue of the journal. To cite the paper please use the doi provided on the Digital Library page.

number of power converters for DC-based DG sources and ESSs, but also can provide higher power quality and transmission capacity in comparison with AC ones [14]-[17].

Hybrid structure is designed to combine the merits of both AC and DC microgrids. The structure includes two independent AC and DC subgrids, each consists of their own DG sources, ESSs and loads; also, in order to avoid the power losses during conversion process, the power transfer between the two subgrids is minimised [18], [19]. The task of interfacing converter is to import/ export active power to/ from DC subgrid, and to provide reactive power to AC subgrid. The architecture of a typical hybrid AC/DC microgrid is shown in Figure 1.

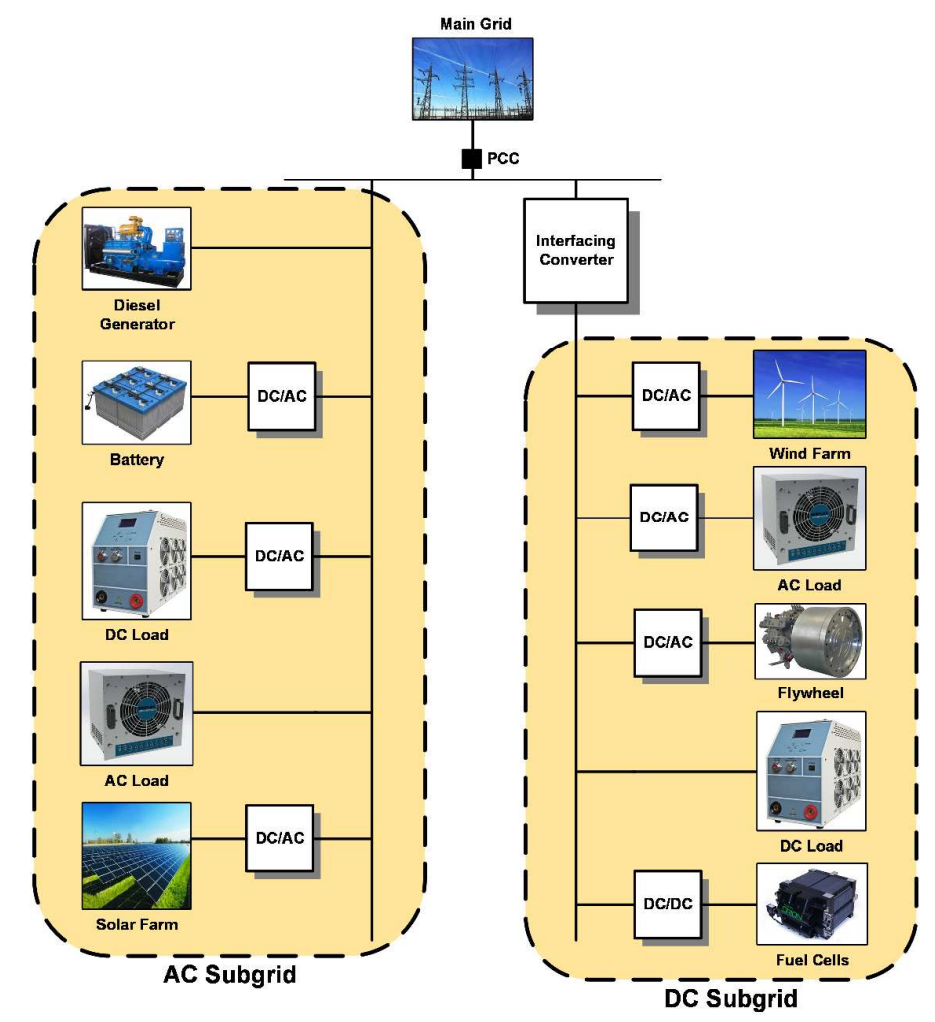

Figure 1. Architecture of a typical hybrid AC/DC microgrid

\section{Protection challenges in microgrids}

\subsection{Protection challenges in AC microgrids and subgrids}

Most conventional distribution systems operate radially, where the power flows unidirectionally from large power plants to the customers. In such systems, since the magnitude of short-circuit current is proportional to the fault location, the protection is performed by overcurrent-based protective devices [20]. Also, the time- 
This article has been accepted for publication in a future issue of this journal, but has not been fully edited.

Content may change prior to final publication in an issue of the journal. To cite the paper please use the doi provided on the Digital Library page.

graded coordination between them enables upstream devices to operate as backup for downstream ones [21]. In recent years, the emergence of microgrids has changed the structure of distribution systems from passive networks into active ones. This change makes the overcurrent-based strategies unable to protect new structures [22], [23].

As mentioned earlier, the fault current contribution of inverter-based DG sources in a microgrid is limited (only two to three times the maximum load current) due to the low thermal capability of their power electronic devices. Therefore, the protective devices of a microgrid containing inverter-based DG sources would operate very slowly or may not be triggered at all in case of a fault event during islanded mode. In addition, the considerable difference between the magnitudes of short-circuit current in grid-connected and islanded modes makes single-setting traditional overcurrent relays unable to protect dual-mode operating microgrids [24], [25]. Therefore, the protection of AC microgrids and subgrids including inverter-based DG sources is not possible using traditional overcurrent protective devices and some new techniques should be devised.

\subsection{Protection challenges in DC microgrids and subgrids}

In spite of numerous merits provided by DC microgrids and subgrids, protection of such systems suffers from several challenges. Some challenges such as limited fault current contribution of inverter-based DG sources in islanded mode or inability of single-setting overcurrent relays in protection of dual-mode microgrids are common between AC and DC systems. Nevertheless, protection of DC ones is influenced by two additional issues, i.e., grounding and lack of natural zero-crossing current.

\subsubsection{Grounding}

Basically, there are two types of faults which can occur in DC networks, namely Line-to-Ground (LG) and Line-to-Line (LL). Even though the latter has typically low fault impedance and causes severe damage to the network, the former is considered as the most frequent fault type in DC networks which is remarkably affected by the type of grounding system [26], [27]. In selection of a proper type of grounding system several factors including minimisation of stray current (leakage current from the conductor to the soil), maximisation of personnel safety (by minimisation of the touch voltage) and fault detection should be taken into account [28].

Corrosion, which is defined as the chemical or electrochemical degradation of metals due to the reaction with the environment such as soil, is the main consequence of stray currents [29]. The phenomenon appears at the 
This article has been accepted for publication in a future issue of this journal, but has not been fully edited.

Content may change prior to final publication in an issue of the journal. To cite the paper please use the doi provided on the Digital Library page.

places where current leaks from the conductors into the soil. Due to the fact that the current changes its transmitting medium (from an electronic environment in the conductor into an ionic one in the soil), an electron to ion transfer is carried out [30]. This electron producing or oxidation reaction is referred to as corrosion if it happens over a long period of time.

The grounding system can also influence the level of touch voltage (potential difference between energised device and the feet of a person in contact with the device). If the level of touch voltage exceeds a certain value (typically $60 \mathrm{~V}$ ), it can endanger the personnel safety. In other words, the maximisation of personnel safety is achieved by minimising the touch voltage [31].

It should be noted that the touch voltage and stray current are inversely proportional with each other through the grounding resistance [32]; for example, the stray current and touch voltage in a solidly grounded system respectively have their highest and lowest values, whereas in a system with large grounding resistance, the value of stray current is about zero and the touch voltage is in its maximum value. In fact, simultaneous minimisation of stray current and touch voltage values is impossible. However, by designing an optimised grounding system their best possible values are achievable [33], [34].

In addition to the values of stray current and touch voltage, fault detection is affected by the type of grounding system. International standard IEC-60364 has specified three families of grounding systems using two-letter codes TN, TT and IT. The first letter which denotes the connection type between source bus and ground can either be T (direct connection) or I (no point is connected) [35]. The second letter represents the connection type between ground or network and the electrical device being supplied, which is either T (ground connection is supplied by a local direct connection to ground) or $\mathrm{N}$ (ground connection is supplied by the electricity supply network, either as a separate protective earth conductor or combined with the neutral conductor).

In a TT-grounded system which includes multiple grounding points, faults do not migrate because of the large impedance of the fault loop. However, the difficulties associated with high-voltage stress and circulating current paths still exist. In TN-grounded systems, both exposed metallic parts and lines are commonly connected to the ground via associated midpoints, but in IT, the exposed metallic parts have a common connection to the ground, whereas lines are not earthed [36]. As a result, detection of faults in a TN-grounded system is simple because of its low grounding resistance, but the personnel safety cannot be ensured since the touch voltage may exceed its 
This article has been accepted for publication in a future issue of this journal, but has not been fully edited.

Content may change prior to final publication in an issue of the journal. To cite the paper please use the doi provided on the Digital Library page.

acceptable threshold. Conversely, IT systems are suitable choices for maximisation of personnel safety due to their low fault currents, but the fault detection in such systems is challenging. However, the second ground fault in IT systems leads to a LL fault with large fault currents and jeopardises the personnel safety [37]. Consequently, designing an optimum grounding model which meets simultaneously both personnel safety and fault detection requirements is a tough engineering challenge.

\subsubsection{Lack of natural zero-crossing current}

Although operation of Circuit Breakers (CBs) in both AC and DC systems is accompanied by an arc phenomenon, mechanism of AC CBs, relying on the natural zero-crossing of the AC currents, enables them to naturally distinguish the arc within the half cycle after tripping. However, due to the lack of natural zerocrossing point in DC currents, the interruption of currents in a DC system is a major problem which not only causes a serious hazard for personnel safety, but also results in the contact erosion of CBs, thereby decreasing their lifetime [38]-[41].

Currently, the commercially available protective devices for DC systems are fuses and CBs [42], [43]. Fuses, which are frequently used in low impedance systems, operate on the principle of melting down a metal wire when overwhelming current flows through it. They must be selected based on the time-current and voltage ratings of system in which they operate. They can function in either AC or DC systems. However, use of fuses in DC systems necessitates accurate calculation of the network time constant due to its direct influence on the fuse operation [42]. More precisely, if the network time constant is less than $2.5 \mathrm{~ms}$, the fuse metal wire is quickly melted and the current is interrupted; in contrast, a large network time constant (more than 6 ms) increases the melting time, and hence, the arc cannot be extinguished rapidly [44]. Additionally, transient overcurrents in a DC network may cause fuse malfunction. Consequently, fuses are not suitable options for protection of DC microgrids, but they still can be used as backup protective devices.

Molded-Case Circuit Breakers (MCCBs), consisting of a quenching chamber, contacts, and a tripping device (thermal-magnetic or electronic), are additional choices for interruption of fault currents [45], [46]. One potential problem with MCCBs in DC systems is that short-circuit currents are supplied mainly by filter capacitors. When a fault incident occurs, these capacitors swiftly discharge into the fault point and leads to large peak currents but for a short period of time. Therefore, the force generated by these currents may be insufficient for opening the contacts of MCCB [47]; in particular, contacts in a highly inductive system may weld closed 
This article has been accepted for publication in a future issue of this journal, but has not been fully edited.

Content may change prior to final publication in an issue of the journal. To cite the paper please use the doi provided on the Digital Library page.

during the fault [48]. For this reason, employment of $\mathrm{CBs}$ is not an ideal solution for interruption of fault currents as well.

\section{Solutions for microgrid protection challenges}

\subsection{Solutions for protection challenges in AC microgrids and subgrids}

As discussed earlier, the traditional overcurrent-based strategies do not have the ability to protect AC microgrids and subgrids due to the drastic difference between magnitudes of fault current in grid-connected and islanded modes. In order to overcome such challenge, a number of strategies have recently been proposed in the literature. In the following subsections, apart from introducing and categorising the most relevant approaches proposed to date, the merits and demerits of each category are further discussed.

\subsubsection{Adaptive protection}

According to [49], adaptive protection is defined as an online system which modifies the preferred protective response to a change in system conditions through an externally generated signal. Adaptive protection schemes can be classified into three main categories including overcurrent, differential and symmetrical components.

\subsubsection{Adaptive overcurrent schemes}

In adaptive overcurrent schemes [50]-[53], a central protection unit is used to periodically store and update three distinct tables namely event, fault current and action tables. Event table lists all possible configurations of the microgrid along with the respective status of DG sources. Subsequently, in accordance with each configuration, the fault current measured by each relay for all possible fault locations is stored in the fault current table. Accordingly, for each set of configurations, action table lists the relay settings for each type of fault along with its time delays. Finally, the central protection unit is able to issue proper tripping signals to the respective relays, based on the status of these three tables in each period. Moreover, in case a relay fails to trip, its upstream or downstream relay (based on action table) operates after a predetermined period of time and provides the secondary protection. Likewise, if a fault takes place in the main grid, the closest microgrid relay to the main grid interrupts the fault current provided by microgrid DG sources, and then the microgrid is transferred to the islanded mode [54]. However, adaptive overcurrent protection strategies suffer from some challenges including: (a) necessity to consider all possible configurations of a microgrid with regard to different 
This article has been accepted for publication in a future issue of this journal, but has not been fully edited.

Content may change prior to final publication in an issue of the journal. To cite the paper please use the doi provided on the Digital Library page.

locations and types of faults, (b) complicated analysis of short-circuit currents in a large microgrid with many radial and looped feeders, (c) costs associated with installation of a communication infrastructure.

\subsubsection{Adaptive differential schemes}

Differential protection schemes operate based on comparison between the measured currents by relays installed at both ends of a protected element (such as busbar, line and transformer). In case a fault occurs in the protected element, the difference between these measured currents exceeds a threshold value and the relays trip to isolate the faulted element from the rest of network. In addition, backup protection can be provided by setting the adjacent upstream and downstream relays of the protected element [51], [55].

In [56], a differential strategy using traditional overcurrent relays and communication links is proposed which is able to protect medium voltage microgrids including both inverter- and synchronous- based DG sources. Even though the economic issues are considered in the scheme, it is unable to provide protection during unbalanced loads.

Sortomme et al. designed another differential-based protection scheme by applying digital relays and Phasor Measurement Units (PMUs) along with communication channels [57]. The scheme provides three levels of protection including instantaneous and comparative voltage relays. Additionally, the protection against HighImpedance Faults (HIFs) is presented in the scheme. Nevertheless, the suggested method is not economical, since the cost related to PMUs is relatively high.

In [58], a different protection scheme is introduced for microgrids including both radial and looped feeders. In the scheme, lines and busbars are protected by means of only differential currents, whereas the protection of DG sources is provided by over- and under-voltage, reverse power flow, and synchronism check relays. Although the developed methodology can provide a robust protection for both grid-connected and islanded modes, it still suffers from problems related to the unbalanced loads and switching transients.

Generally, the main drawbacks of differential protection approaches are: (a) need for communication system as a key element, while its failure endangers protection of microgrid, (b) deployment of costly synchronised measurement devices, (c) difficulties resulting from unbalanced loads and transients during connection or disconnection of DG sources. 
This article has been accepted for publication in a future issue of this journal, but has not been fully edited.

Content may change prior to final publication in an issue of the journal. To cite the paper please use the doi provided on the Digital Library page.

\subsubsection{Adaptive protection schemes based on symmetrical components}

The proposed protection schemes in the category substantially apply principles of symmetrical components and enable overcurrent-based strategies to protect microgrids in both grid-connected and islanded modes. The main proposal in the area is put forward by Nikkhajoei and Lasseter in 2006 [59]. In their proposal, they make use of zero- and negative- sequence currents to detect and isolate, respectively, single-line-to-ground and lineto-line faults in islanded mode of operation. However, the devised solution has not the ability to protect microgrids during HIFs. Furthermore, the operation of the protection scheme requires communication links.

In [60], a Microprocessor-Based Relay (MBR) along with a protection strategy is designed. The strategy which is able to protect low voltage microgrids against both solid and HIFs, operates by applying zero- and negative- sequence components. The main feature of the strategy is that it does not require communication links. However, the proposed method is not capable of protecting microgrids including mesh feeders.

The authors of [61] developed another protection scheme based on only positive-sequence components. The proposed scheme, is based upon a MBR along with PMUs and a digital communication system to protect microgrids including both radial and looped feeders against different types of faults. The designed MBRs have the ability to update their pickup values after any change in the structure of microgrid, thereby protecting microgrids against subsequent faults. Even though the proposed protection scheme remedies the drawbacks of the previous works, it is not economical due to the high price of PMUs.

The main issues related with the implementation of the above-mentioned schemes are: (a) necessity to extensive communication infrastructure in some proposals that may fail at some point, jeopardising the whole microgrid protection, (b) inability to provide protection for looped microgrids, (c) high costs associated with deployment of PMUs.

\subsubsection{Distance protection}

Distance protection schemes which offer a high selectivity is another way to protect AC microgrids and subgrids. The installed distance relays in the scheme are responsible for calculation of impedance using the measured voltage and current at their location, by which they are able to detect the fault occurrences. Prior to fault occurrence, the measured impedance value is high because it includes the load impedance, while in case of a fault event on the network lines, the value becomes equivalent to only line impedance and decreases. As a 
This article has been accepted for publication in a future issue of this journal, but has not been fully edited.

Content may change prior to final publication in an issue of the journal. To cite the paper please use the doi provided on the Digital Library page.

result, the fault in each zone can be detected and located by comparison between the measured impedance values before and after the fault [62], [63].

The main study in this category is accomplished by Dewadasa and his research group in references [64], [65]. In the proposed protection scheme, new admittance relays are developed based on characteristics of inverse time tripping. The developed relays have the ability to provide protection in their forward and inverse directions against different kinds of faults. However, some shortcomings of this methodology include: (a) errors resulting from fault resistance in measured impedances by relays, (b) complications associated with impedance measurements in short lines.

\subsubsection{Pattern recognition schemes}

In reference [66], a new microgrid protection scheme is developed by applying a time-frequency transform which has the ability to protect radial and looped microgrids against different types of faults in both gridconnected and islanded mode. In the developed scheme, first, S-transform is used to extract the spectral energy contents of the fault current signals, measured at both ends of each line. Subsequently, fault patterns are registered by differential energy computations. Based on the predetermined threshold values (in accordance with each type of fault) on differential energy, the protection scheme is able to detect and isolate the faulted line. With regard to the indicated simulation results, the differential energy can be a suitable criterion, since it remarkably varies for a faulty phase in comparison with healthy ones. Moreover, the developed strategy is immune to the noise and less sensitive to synchronisation errors. However, the main challenge in the pattern recognition schemes is that the system has to be trained. The training is usually achieved by simulations and not real cases and hence it cannot be practically feasible.

\subsubsection{Harmonics content based schemes}

Another strategy for protection of microgrids is developed by a research group at the University of Bath, mainly formed by H. Al-Nasseri and M. A. Redfern, based on harmonics content of inverter output voltage [67]. During grid-connected mode, distribution system acts as a low-impedance voltage and maintains a low distorted voltage on the inverter terminals. However, when the microgrid is transferred to the islanded mode as a result of fault incident, the impedance at inverter terminals increases due to the disconnection of the low-impedance main grid. Therefore, current harmonics in the output current of the inverter leads to an increase in the magnitudes of 
This article has been accepted for publication in a future issue of this journal, but has not been fully edited.

Content may change prior to final publication in an issue of the journal. To cite the paper please use the doi provided on the Digital Library page.

voltage harmonics in the terminal voltage. In the proposed strategy, a relay is used to monitor Total Harmonic Distortion (THD) of the terminal voltage of each inverter-based DG unit which trips the local CBs once the THD exceeded a predetermined threshold value, and the fault is proven that to be within that relay's protection zone. Communication links are also employed for comparison of THD values measured at different inverterbased DG units.

In [68], another protection scheme is proposed based on harmonic analysis, in which the fault is detected using the proportion of zero sequence current to positive sequence current of fifth harmonic. Since the proposed scheme in this paper employs zero sequence current for detection of fault, only single line to ground faults can be detected using this method.

The work reported in [69] presents a new protection scheme based on low harmonics components. In the presented scheme, through injecting a certain proportion of fifth harmonics to the fault current, the protection device can detect the fault according to the low harmonics components extracted by the digital relay. The main advantage of this method is that it does not rely on large fault currents, and hence, some limitations of the traditional overcurrent-based protection strategies are resolved.

The main challenges associated with the harmonics content based schemes are: (a) inability to detect HIFs, (b) time delays incurred by computations and filtering, (c) in some methods, there are no considerations for distribution transformer connection which are common in distribution networks; more precisely, a delta-wye transformer has a significant impact on the fault current and voltage waveform.

\subsubsection{Wavelet transform based schemes}

Wavelet transform based schemes detect faults by extracting the transient components containing fault information from network distortions. The wavelet transform breaks the transients down into a series of wavelet components, each corresponding to a time domain signal which covers a specific frequency band containing more detailed information.

In [70], a digital protection scheme is proposed, in which Wavelet Packet Transform (WPT) is used to extract the first-level high-frequency sub-band contents present in the d-q-axis current components, and are considered as signature for detection and location of faults. In the case of a transient disturbance, these contents have two possible relocations as: (a) Frequency components are relocated in low-frequency half-band with fixed locations 
This article has been accepted for publication in a future issue of this journal, but has not been fully edited.

Content may change prior to final publication in an issue of the journal. To cite the paper please use the doi provided on the Digital Library page.

and decaying magnitudes. Such relocated frequency components are pertinent to transient disturbances initiated by events which do not make changes to system configuration and/or connections. These transient disturbances are of the non-fault type. (b) Frequency components are relocated in low-frequency half-band and in highfrequency half-band with changing locations and magnitudes due to non-periodic and non-stationary characteristics. Such relocated frequency components are associated with transient disturbances caused by changes in system configuration and/or connections. These transient disturbances fall under the fault type.

Reference [71] proposes an intelligent protection scheme using combination of wavelet transform and decision tree which consists of branches and decision points. Branches represents different characteristics of a signal, and decision points are used for detection of fault type. In the proposed scheme, in accordance with signal properties extracted by wavelet transform, associated branches are analysed, and the decision points which detects the fault type is determined.

In [72], Maximal Overlapping Discrete Wavelet Transform (MODWT) and Decision Tree are used to detect HIFs in microgrids. In the developed strategy, fault currents are decomposed using MODWT to obtain the details and approximation coefficients. Then, some statistical features are estimated using these coefficients and are employed to train Decision Tree for accurate detection of HIFs.

Another wavelet transform based protection scheme is developed in [73] using digital relays. In the developed scheme, first, the dq0 decomposition method is used to reduce the relays' computation time; subsequently, the wavelet transform is applied to decompose dq0 components of voltage and current signals. Finally, faults are located and cleared using product of high-frequency details of current and voltage.

The main challenge in implementation of wavelet based schemes is that the high level of noise in voltage or current signals may further degrade the performance of the proposed schemes.

\subsubsection{Traveling wave based schemes}

The main work in this field was conducted by Shi et al. at Tsinghua University in 2010. In their proposed scheme, current traveling waves and busbar voltages are used for detection of fault events. Current traveling waves are measured by current transformers in lines and wavelet multi-resolution analysis is employed for decomposition of traveling wave signals, then, the initial traveling waves are compared with each other in terms of magnitude and polarity to identify the faulted feeder [74]. 
This article has been accepted for publication in a future issue of this journal, but has not been fully edited. Content may change prior to final publication in an issue of the journal. To cite the paper please use the doi provided on the Digital Library page.

In [75], another protection strategy is proposed based on the time and polarity features of initial current traveling waves using Mathematical Morphology technology and backup protection strategy. Traveling waves are analysed to locate the fault using a Rogowski sensor. If the first two wavefronts detected by a protective device have the same polarity, the fault is located within the relay's zone of protection as depicted in Figure 2.

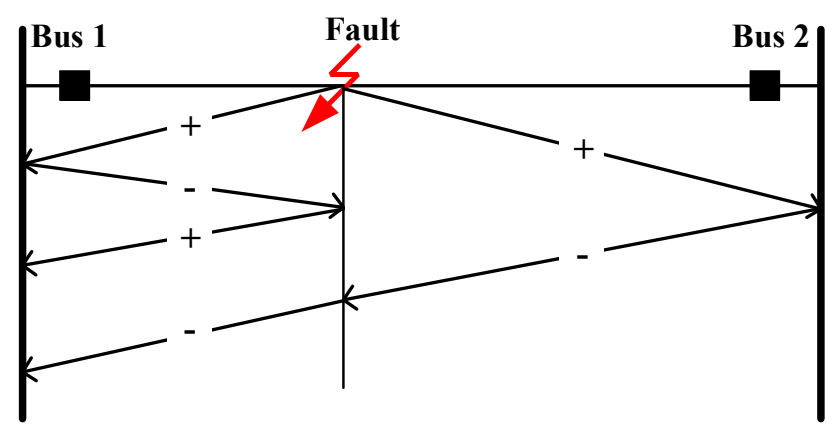

Fig. 2. Protection using traveling waves [75]

Reference [76] presents a strategy for protection of inverter dominated microgrids based on current traveling waves with simplified polarity detection and new logics introduced for meshed networks and feeders with single-end measurement. The presented protection strategy provides ultrafast response for different fault types in both grid-connected and islanded modes. However, the strategy requires a low-bandwidth communication system to achieve high-speed operation and adequate discrimination level in meshed networks.

Even though traveling wave based strategies are suitable options to locate fault in transmission lines, accurate fault location in microgrids requires much higher sampling rates to achieve higher resolution; for example, the time difference between the first transient wave and the second transient wave arriving at the sensor in the transmission line is in a magnitude of seconds corresponding to a wave traveling distance of about $100 \mathrm{~km}$, whereas in a microgrid the time difference would be in a magnitude of microseconds if such concept would still apply.

\subsection{Solutions for protection challenges in DC microgrids and subgrids}

Although the majority of proposed protection schemes for AC microgrids and subgrids can be designed compatible with DC ones to overcome the common challenges, provision of a robust scheme for DC ones also necessitates addressing the challenges associated with grounding and lack of natural zero-crossing current. The following subsections review the main proposed approaches, attempting to resolve such challenges. 
This article has been accepted for publication in a future issue of this journal, but has not been fully edited.

Content may change prior to final publication in an issue of the journal. To cite the paper please use the doi provided on the Digital Library page.

\subsubsection{Reconfigurable grounding systems}

As mentioned in Subsection 3.2.1, personnel safety and fault detection are two contradictory requirements which are affected by grounding system. In fact, best personnel safety and fault detection cannot be achieved in a certain grounding system. Hence, some alternative solutions have recently appeared in literature which try to ponder both of these requirements by applying reconfigurable grounding systems. More precisely, in such grounding systems, the network normally operates in ungrounded mode to minimise corrosion phenomenon resulting from high stray currents, but in case of sensing an unacceptable level of touch voltage, it automatically transfers to the grounded mode. However, it switches back to the ungrounded mode after clearance of abnormal operating condition.

The most basic structure of a reconfigurable system, referred to as diode grounded system, is shown in Figure 3(a) [77]. As shown in the figure, diode grounded system contains a direct metallic connection of the negative bus to the earth by means of a diode circuit. In case a certain threshold voltage is reached, the current is allowed to flow through diode circuit to get dissipated in order that the personnel safety is ensured. However, due to the fact that corrosion cannot be entirely obviated by dint of diode grounded systems, they necessitate regular maintenance.

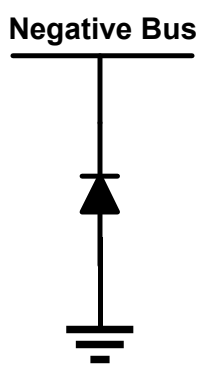

(a)

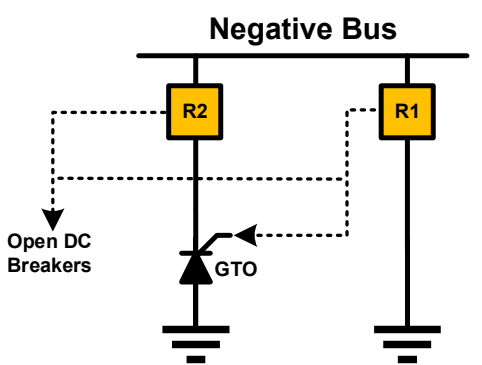

(b)

Figure 3. Structures of reconfigurable grounding systems: (a) Diode-grounded system. (b) Thyristorgrounded system.

In order to possess an active control over the grounding instances, thyristor grounded system was developed in [28]. In the proposed system, (as depicted in Figure 3(b)), an overvoltage relay (R1) continuously monitors the difference between negative bus and ground voltage magnitudes and triggers the thyristor gate once it exceeded a predetermined value. Furthermore, the system is equipped with a current sensor (R2) in order to check the status of the flowing current. If the level of sensed current was lowered, the system can be switched 
This article has been accepted for publication in a future issue of this journal, but has not been fully edited. Content may change prior to final publication in an issue of the journal. To cite the paper please use the doi provided on the Digital Library page.

back to the ungrounded mode. Otherwise, a positive to ground fault event is the most probable reason that DC breakers must be swiftly opened.

The salient feature of the thyristor grounded system in comparison with diode one is that it sustains the system ungrounded, unless a dangerous voltage is sensed; therefore, the thyrsitor grounded system considerably minimises the stray current and its negative consequences. The levels of touch voltage and stray current in different kinds of grounding systems are compared with each other in Table 1.

Table 1. Levels of touch voltage and stray current in different kinds of grounding systems

\begin{tabular}{c|c|c}
\hline Grounding System Type & Touch Voltage Level & Stray Current Level \\
\hline \hline Ungrounded & High & Low \\
\hline Solidly-grounded & Low & High \\
\hline Diode-grounded & Moderate/Low & Moderate/High \\
\hline Thyristor-grounded & Moderate/High & Moderate/Low \\
\hline
\end{tabular}

\subsubsection{DC current interruption approaches}

As discussed before, protection of DC microgrids by means of fuses and CBs has some performance restrictions due to their inherent large time constants and time delays, respectively. In order to overcome such limitations, Tang and his colleague presented a new current interruption approach for Multi-Terminal DC (MTDC) grids and navy shipboard DC Zonal Electric Distribution (DCZED) systems by means of electromechanical switches. In their proposed approach, they split the network into several zones and make use of noload switches to cease the fault currents [78], [79]. More precisely, once a fault was recognised in a zone, converters supplying the network de-energise the bus(s), and subsequently the faulted zone is isolated by noload switches. Finally, the rest of network is re-energised to continue its operation. The main problem with the proposed approach is that it entirely shuts down the network after the fault detection which may not be necessary.

An alternative approach was proposed using Solid State Circuit Breakers (SSCBs) at DC terminals of Voltage Source Converters (VSCs) or on the downstream side of DC/DC converters [80], [81]. The approach can be implemented by different solid state switches such as Gate Turn-Off (GTO) thyristors, Insulated-Gate Bipolar 
This article has been accepted for publication in a future issue of this journal, but has not been fully edited.

Content may change prior to final publication in an issue of the journal. To cite the paper please use the doi provided on the Digital Library page.

Transistors (IGBTs), and Insulated-Gate Commutated Thyristors (IGCTs). However, employment of each of the switch topologies has its own merits and demerits [80]. SSCBs are also equipped with a parallel combination of a snubber circuit and Metal-Oxide Varistors (MOVs) to dissipate power during the interruption of fault currents. Notwithstanding advantages of SSCBs, some of their demerits make them disputable. Contrary to mechanical contacts, the maximum operating voltage and current of SSCBs are limited in order to protect their switching devices. Overrating of SSCBs also leads to exponential increase of costs. Furthermore, the resistance of SSCBs is much larger than that of mechanical $\mathrm{CBs}$, leading to additional losses during the on-state and thus, the reduction of the overall system efficiency.

In [82], Baran and Mahajan presented a new scheme to limit and interrupt the fault currents through controlling the duty cycle of converters. Once a fault incident is detected on the downstream side, proper protection commands are issued to actively limit the fault current or to turn off the converter switches. In case of a switch hard turn-off command, the current from the primary side is rapidly ceased, whereas the load side current is interrupted after the stored energy in the output inductor was dissipated by freewheeling through the converter freewheeling diodes. But in case a current limiting command issues, the fault current is limited to an acceptable value or driven to zero, and then interrupted.

In 2009, Salomonsson et al. presented an approach based on proper selection of protective devices corresponding to the fault withstanding capability of each network component [83]. According to the research, ultrafast hybrid CBs are proposed for protection of power electronic devices in order to quickly interrupt the current flowing from their sensitive switching devices including IGBTs and diodes. On the contrary, regular CBs are suggested to protect batteries, since they can withstand drastically large currents without damage. Moreover, the application of fuses and MCCBs for protection of network feeders is introduced. It is also specified that MCCBs should be installed closer to the loads due to their capability in simultaneous interruption of currents in both positive and negative poles, whereas fuses are more suitable to be installed closer to the buses, since their magnetic sensing provides good selectivity.

Three years later, a new type of solid state breakers, termed as z-source breaker, was introduced [84]. The breakers are able to automatically commutate a main-path Silicon-Controlled Rectifier (SCR) during a fault by means of a z-source LC circuit. In spite of swift operation of the z-source CBs, their resonant circuit is strongly dependent on the fault characteristics, and the parameters of upstream and downstream components. In addition, voltage oscillations resulting from resonant circuit may lead to overvoltage on other network components. 
This article has been accepted for publication in a future issue of this journal, but has not been fully edited.

Content may change prior to final publication in an issue of the journal. To cite the paper please use the doi provided on the Digital Library page.

In [85], Fletcher and his research group proposed unit protection approach against non-unit ones which often overlook the high sensitivity of the network response to the fault impedance. Also, the presented work attempted to identify the means by which the fast and effective protection system operation is achieved, whilst seeking to minimise installation costs, against a set of very strict operating requirements. Finally, they presented a flexible design framework for unit protection of DC microgrids with a high selectivity, and considering optimum operating speed and total cost of the system. In addition, the results of the study indicated that their proposed protection scheme provides a better fault discrimination in comparison with previous studies.

The authors of [39] developed a new protection scheme for low voltage DC-bus microgrids to isolate the smallest possible faulted area such a way that allows the rest of network maintains operating. In the proposed strategy, they make use of a loop-type DC bus along with segment controllers, consisting one master and two slave units, between the loop components. First, the master unit receives the values of current measured by the slave units, and then issues the proper disconnection commands to the bus switches depending upon the difference between these values.

\section{Future directions and open issues}

Realisation of smart grids in the future needs that all of their technical, economic and environmental challenges are resolved. Providing a robust protection in both grid-connected and islanded mode of operation is one of the most important ones. Development of hybrid AC/DC microgrids as an integrated part of smart grids necessitates intelligent coordination among communication, control and protection fields. As a result, in order to address the discussed protection challenges in this paper, the simultaneous development of these three fields in microgrids will be necessary.

\subsection{Development of communication infrastructures}

Communication systems play a key role in the operation of microgrids by providing a bidirectional connection between network components and management unit. The communication networks in a microgrid can be classified into three main clusters including Home Area Networks (HANs), Field Area Networks (FANs) and Wide Area Networks (WANs) [86]. HANs are frequently employed to inform the customers about their electricity consumption through bidirectional communications between their electrical devices and smart meters with a bandwidth about 10 to $100 \mathrm{Kbps}$ (per each electrical device). Bluetooth, Zigbee, and Wireless-Fidelity 
This article has been accepted for publication in a future issue of this journal, but has not been fully edited.

Content may change prior to final publication in an issue of the journal. To cite the paper please use the doi provided on the Digital Library page.

(Wi-Fi) are some communication technologies which can be deployed in HANs [87], [88]. FANs are responsible for sending the collected data by smart meters (via HANs) to the control centre. Moreover, the control signals from the control centre to the customer's electrical devices are transmitted through this network. The communication technologies which can be employed in FANs encompass Wi-Fi, Worldwide Interoperability for Microwave Access (WiMax), Radio Frequency (RF), Power Line Communication (PLC), General Packet Radio Service (GPRS) and Enhanced Data rates for GSM Evolution (EDGE) [89]. WANs are networks with high bandwidth which provide bidirectional communications between microgrids and main grid. They can also be utilised as external access networks to provide information operators. WiMax is the most common technology for such networks, since it can provide a vast coverage [90].

With regard to the above-mentioned communication technologies, there are still some issues which call for further research and analysis. These issues include: (a) economically analysis of high data rate and coverage technologies such as Long Term Evolution (LTE), (b) energy-efficiency enhancement by means of relaying techniques, Coordinated Multi-Point (CoMP) technology or mobile relays [91], (c) employment of combined communication technologies such as optical-wireless.

\subsection{Development of combined control and protection schemes}

Combination of control and protection schemes in future hybrid AC/DC microgrids can be effective in resolving the following challenges: (a) self-healing which is an ability to provide fast recovery and resilience of the power system in response to the short-circuit conditions [92], (b) Low-Voltage Ride Through (LVRT) which is defined as the capability of generators to stay connected in short periods of lower electric network voltage, (c) driving current to zero prior to its interruption by CBs. However, development of combined control and protection schemes necessitates coordination with communication and information infrastructures.

\subsection{Development of smart control and protection devices}

Solid State Transformers (SSTs), as one of the most innovative technologies, have been attracted much attention in recent years [93]. SSTs, consisting of high-power semiconductor components, high frequency transformers and control circuitry, not only have the ability to step up or down the levels of voltage, but also can provide the following advantages [92]: (a) control of power flow, (b) provision of AC and DC interface, (c) limitation of short-circuit currents, (d) seamless transition between microgrid operating modes. However, 
This article has been accepted for publication in a future issue of this journal, but has not been fully edited.

Content may change prior to final publication in an issue of the journal. To cite the paper please use the doi provided on the Digital Library page.

employment of SSTs in the future hybrid AC/DC microgrids necessitates more economic and reliability analysis.

\section{Conclusion}

Penetration of microgrids is currently growing around the world, since they offer less environmental impact, low running cost, and high reliability and power quality. Hybrid AC/DC microgrids are composed of independent AC and DC subgrids, in which all AC- and DC-based DG sources and loads are connected to the buses directly or indirectly through power electronic interfaces. In this study, after introducing the structure of hybrid microgrids, difficulties associated with the protection of AC and DC microgrids and subgrids were analysed; afterwards, a comprehensive review of the most recent solutions in the scientific literature addressing the difficulties was performed. Lastly, future directions and open issues for implementation of robust protection systems in hybrid $\mathrm{AC} / \mathrm{DC}$ microgrids were investigated.

\section{Acknowledgements}

This work is supported in part by the National Natural Science Foundation of China (Grant No. 51120175001), and in part by the National Key Research and Development Plan of China (Grant No. 2016YFB0900600).

\section{References}

[1] K. Das, A. Nitsas, M. Altin, A. D. Hansen, and P. E. Sørensen, "Improved Load-Shedding Scheme Considering Distributed Generation,” vol. 32, no. 1, pp. 515-524, 2017.

[2] H. Liao, and J. V. Milanović, "Methodology for the analysis of voltage unbalance in networks with single-phase distributed generation," IET Gener. Transm. Distrib., vol. 11, no. 2, pp. 550-559, 2017.

[3] B. R. Pereira, G. R. M. da Costa, J. Contreras, and J. R. S. Mantovani, "Optimal Distributed Generation and Reactive Power Allocation in Electrical Distribution Systems," IEEE Trans. Sustain. Energy, vol. 7, no. 3, pp. 975-984, 2016.

[4] H. Jiayi, J. Chuanwen, and X. Rong, "A review on distributed energy resources and MicroGrid," Renew. Sustain. Energy Rev., vol. 12, no. 9, pp. 2465-2476, 2008.

[5] A. Gururani, S. R. Mohanty, and J. C. Mohanta, "Microgrid protection using Hilbert-Huang transform 
This article has been accepted for publication in a future issue of this journal, but has not been fully edited.

Content may change prior to final publication in an issue of the journal. To cite the paper please use the doi provided on the Digital Library page.

based-differential scheme,” IET Gener. Transm. Distrib., vol. 10, no. 15, pp. 3707-3716, 2016.

[6] J. J. Justo, F. Mwasilu, J. Lee, and J. W. Jung, “AC-microgrids versus DC-microgrids with distributed energy resources: A review,” Renew. Sustain. Energy Rev., vol. 24, pp. 387-405, 2013.

[7] E. Ragaini, E. Tironi, S. Grillo, L. Piegari, and M. Carminati, “Ground fault analysis of low voltage DC micro-grids with active front-end converter," 3rd Renew. Power Gener. Conf. (RPG 2014), Naples, Italy, pp. 1-6, 2014.

[8] H. Lotfi, and A. Khodaei, "Hybrid AC / DC Microgrid Planning," IEEE Trans. Power Syst., vol. 8, no. 1, pp. 296-304, 2016.

[9] A. Hooshyar, and R. Iravani, "Microgrid Protection," in Proceedings of the IEEE, vol. 105, no. 7, pp. $1332-1353,2017$.

[10] M. H. Cintuglu, T. Ma, and O. A. Mohammed, "Protection of Autonomous Microgrids using AgentBased Distributed Communication,” IEEE Trans. Power Deliv., vol. 32, no. 1, pp. 351-360, 2016.

[11] K. Lai, M. S. Illindala, and M. A. Haj-Ahmed, "Comprehensive Protection Strategy for an Islanded Microgrid Using Intelligent Relays,” IEEE Trans. Ind. Appl., vol. 8, no. 99, pp. 47-55, 2016.

[12] E. Planas, J. Andreu, J. I. Gárate, I. Martínez De Alegría, and E. Ibarra, “AC and DC technology in microgrids: A review," Renew. Sustain. Energy Rev., vol. 43, pp. 726-749, 2015.

[13] M. E. Nassar, and M. M. A. Salama, “A novel branch-based power flow algorithm for islanded AC microgrids," Electr. Power Syst. Res., vol. 146, pp. 51-62, 2017.

[14] C. N. Papadimitriou, E. I. Zountouridou, and N. D. Hatziargyriou, "Review of hierarchical control in DC microgrids," Electr. Power Syst. Res., vol. 122, pp. 159-167, 2015.

[15] S. B. Fei Gao, C. Alessandro, P. Chintan, W. Pat, I. H. Christopher, and A. Greg, "Comparative Stability Analysis of Droop Control Approaches in Voltage Source Converters-Based DC Microgrids," IEEE Trans. Power Electron., vol. 32, no. 3, pp. 2395-2415, 2016.

[16] A. Tah and D. Das, “An Enhanced Droop Control Method for Accurate Load Sharing and Voltage Improvement of Isolated and Interconnected DC Microgrids," IEEE Trans. Sustain. Energy, vol. 7, no. 3, pp. 1194-1204, 2016.

[17] L. Meng, T. Dragicevic, J. Roldan-Perez, J. C. Vasquez, and J. M. Guerrero, "Modeling and Sensitivity Study of Consensus Algorithm-Based Distributed Hierarchical Control for DC Microgrids," IEEE 
This article has been accepted for publication in a future issue of this journal, but has not been fully edited. Content may change prior to final publication in an issue of the journal. To cite the paper please use the doi provided on the Digital Library page.

Trans. Smart Grid, vol. 7, no. 3, pp. 1504-1515, 2016.

[18] W. Feng, T. K. Jet, L. Kaiyuan, Y. H. Goh, B. Si, and H. Chew, "Harmonic Mitigation of Hybrid AC/ DC Micro-grids with PMSG," Renewable Power Generation (RPG) 2016, 5th IET International Conference on, London, U.K., pp. 1-5, 2016.

[19] E. Unamuno, and J. A. Barrena, "Hybrid ac/dc microgrids - Part I: Review and classification of topologies,” Renew. Sustain. Energy Rev., vol. 52, pp. 1251-1259, 2015.

[20] E. C. Piesciorovsky, and N. N. Schulz, "Fuse relay adaptive overcurrent protection scheme for microgrid with distributed generators," IET Gener. Transm. Distrib., vol. 11, no. 2, pp. 540-549, 2017.

[21] Z. Liu, H. K. Hoidalen, and M. M. Saha, “An intelligent coordinated protection and control strategy for distribution network with wind generation integration," CSEE J. Power Energy Syst., vol. 2, no. 4, pp. 23-30, 2016.

[22] A. K. Sahoo, "Protection of microgrid through coordinated directional over-current relays," 2014 IEEE Global Humanitarian Technology Conference - South Asia Satellite (GHTC-SAS), Trivandrum, India, pp. 129-134, 2014.

[23] N. K. Choudhary, S. R. Mohanty, and R. K. Singh, "A review on Microgrid protection," 2014 International Electrical Engineering Congress (iEECON), Chonburi, Thailand, pp. 1-4, 2014.

[24] D. M. Bui, S. L. Chen, K. Y. Lien, and J. L. Jiang, "Fault protection solutions appropriately used for ungrounded low-voltage AC microgrids," Proc. 2015 IEEE Innov. Smart Grid Technol. - Asia, ISGT ASIA 2015, Bangkok, Thailand, pp. 4066-4071, 2016.

[25] A. Hussain, M. Aslam, and S. M. Arif, "N-version programming-based protection scheme for microgrids: A multi-agent system based approach,” Sustain. Energy Grids Networks, vol. 6, pp. 35-45, 2016.

[26] A. Meghwani, S. Srivastava, and S. Chakrabarti, "A Non-Unit Protection Scheme for DC Microgrid Based on Local Measurements," IEEE Trans. Power Deliv., vol. 32, no. 1, pp. 172-181, 2016.

[27] M. Monadi, C. Gavriluta, A. Luna, I. Candela, and P. Rodriguez, "Centralized Protection Strategy for Medium Voltage DC Microgrids," IEEE Trans. Power Deliv., vol. 32, no. 1, pp. 430-440, 2016.

[28] D. Paul, "DC traction power system grounding," 2001 IEEE Industry Applications Conference, 36th IAS Annual Meeting, Chicago, USA, pp. 2133-2139, 2001. 
This article has been accepted for publication in a future issue of this journal, but has not been fully edited.

Content may change prior to final publication in an issue of the journal. To cite the paper please use the doi provided on the Digital Library page.

[29] S. A. Memon, and P. Fromme, "Stray Current Corrosion and Mitigation: A synopsis of the technical methods used in dc transit systems," IEEE Electrification Magazine, vol. 2, no. 3, pp. 22-31, 2014.

[30] I. Cotton, C. Charalambous, P. Aylott, and P. Ernst, "Stray current control in DC mass transit systems," IEEE Trans. Veh. Technol., vol. 54, no. 2, pp. 722-730, 2005.

[31] A. Ibrahem, A. Elrayyah, Y. Sozer, and A. De Abreu, "DC Railway System Emulator for Stray Current and Touch Voltage Prediction," IEEE Trans. Ind. Appl., vol. 53, no. 1, pp. 439-446, 2016.

[32] M. Niasati, and A. Gholami, "Overview of stray current control in dc railway systems," 2008 International Conference on Railway Engineering - Challenges for Railway Transportation in Information Age, Hong Kong, China, pp. 1-6, 2008.

[33] M. Mitolo, and H. Liu, “Touch Voltage Analysis in Low-Voltage Power Systems Studies," IEEE Trans. Ind. Appl., vol. 52, no. 1, pp. 556-559, 2016.

[34] F. Augusto, H. León, J. Manuel, and P. Quevedo, "Design and Construction of a Dynamic System for Step and Touch Voltage Measurements for Grounding Systems," 2011 International Symposium on Lightning Protection, Fortaleza, Brazil, pp. 278-283, 2011.

[35] IEC 60364-1 Low-Voltage Electrical Installations-Part 1: Fundamental Principles, Assessment of General Characteristics, Definitions, IEC 60364-1, 2005.

[36] T. Dragičević, X. Lu, J. C. Vasquez, and J. M. Guerrero, "DC Microgrids - Part II : A Review of Power Architectures, Applications, and Standardization Issues,” IEEE Trans. Power Electron., vol. 31, no. 5, pp. 3528-3549, 2016.

[37] G. Madingou, M. Zarghami, and M. Vaziri, "Fault detection and isolation in a DC microgrid using a central processing unit,” 2015 IEEE Power Energy Soc. Innov. Smart Grid Technol. Conf., Washington, DC, U.S., pp. 1-5, 2015.

[38] D. J. Becker, and B. J. Sonnenberg, "DC microgrids in buildings and data centers," 2011 IEEE 33rd International Telecommunications Energy Conference (INTELEC), Amsterdam, Netherlands, pp. 1-7, 2011.

[39] J. Do Park, J. Candelaria, L. Ma, and K. Dunn, "DC ring-bus microgrid fault protection and identification of fault location," IEEE Trans. Power Deliv., vol. 28, no. 2, pp. 779-787, 2013.

[40] C. Yuan, M. a. Haj-ahmed, and M. Illindala, "Protection Strategies for Medium Voltage Direct Current 
This article has been accepted for publication in a future issue of this journal, but has not been fully edited. Content may change prior to final publication in an issue of the journal. To cite the paper please use the doi provided on the Digital Library page.

Microgrid at a Remote Area Mine Site,” IEEE Trans. Ind. Appl., vol. 51, no. 4, pp. 2846-2853, 2015.

[41] T. Sakagami, "Simulation to Optimize a DC Microgrid in Okinawa," 2016 IEEE International Conference on Sustainable Energy Technologies (ICSET), Hanoi, Vietnam, pp. 214-219, 2016.

[42] J. P. Brozek, "DC overcurrent protection - Where we stand," Conference Record of the 1992 IEEE Industry Applications Society Annual Meeting, Houston, TX, USA, pp. 1306-1310, 1992.

[43] G. D. Gregory, “Applying Low Voltage Circuit Breakers in Direct Current Systems,” Proceedings of 1994 IEEE Industry Applications Society Annual Meeting, Denver, CO, U.S., pp. 2293-2302, 1994.

[44] IEEE Guide for the Protection of Stationary Battery Systems. IEEE Standard 1375-1998, 1998.

[45] Y. Liu, D. Chen, H. Yuan, L. Ji, and Z. Ma, "Research of Dynamic Optimization for the Cam Design Structure of MCCB," IEEE Trans. Components, Packag. Manuf. Technol., vol. 6, no. 3, pp. 390-399, 2016.

[46] L. Ji, D. Chen, Y. Liu, and X. Li, "Analysis and improvement of linkage transfer position for the operating mechanism of MCCB,” IEEE Trans. Power Deliv., vol. 26, no. 1, pp. 222-227, 2011.

[47] R. M. Cuzner, and G. Venkataramanan, "The status of DC micro-grid protection," 2008 IEEE Industry Applications Society Annual Meeting, Edmonton, Alta., Canada, pp. 1-8, 2008.

[48] H. Sun, M. Rong, Z. Chen, C. Hou, and Y. Sun, "Investigation on the Arc Phenomenon of Air DC Circuit Breaker,” IEEE Trans. Plasma Science, vol. 42, no. 10, pp. 2706-2707, 2014.

[49] K. H. Zheng, and M. C. Xia, "Impacts of microgrid on protection of distribution networks and protection strategy of microgrid," 2011 International Conference on Advanced Power System Automation and Protection, Beijing, China, pp. 356-359, 2011.

[50] S. T. Ustun, "Design and development of a communication assisted microgrid protection system," Ph.D. thesis, School of Engineering and Science, Faculty of Health, Engineering and Science, Victoria University, 2013.

[51] T. S. Ustun, C. Ozansoy, and A. Zayegh, "Fault current coefficient and time delay assignment for microgrid protection system with central protection unit," IEEE Trans. Power Syst., vol. 28, no. 2, pp. 598-606, 2013.

[52] A. Oudalov and A. Fidigatti, “Adaptive network protection in micro- grids," International Journal of Distributed Energy Resources, vol. 4, no. 3, pp. 201-205, 2009. 
This article has been accepted for publication in a future issue of this journal, but has not been fully edited.

Content may change prior to final publication in an issue of the journal. To cite the paper please use the doi provided on the Digital Library page.

[53] A. H. Etemadi, and R. Iravani, "Overcurrent and overload protection of directly voltage-controlled distributed resources in a microgrid," IEEE Trans. Ind. Electron., vol. 60, no. 12, pp. 5629-5638, 2013.

[54] H. Laaksonen, D. Ishchenko, and A. Oudalov, “Adaptive Protection and Microgrid Control Design for Hailuoto Island,” IEEE Trans. Smart Grid, vol. 5, no. 3, pp. 1486-1493, 2014.

[55] T. S. Ustun, C. Ozansoy, and A. Zayegh, "Modeling of a centralized microgrid protection system and distributed energy resources according to IEC 61850-7-420," IEEE Trans. Power Syst., vol. 27, no. 3, pp. 1560-1567, 2012.

[56] S. Conti, L. Raffa, and U. Vagliasindi, "Innovative solutions for protection schemes in autonomous MV micro-grids," 2009 International Conference on Clean Electrical Power, Capri, Italy, pp. 647-654, 2009.

[57] E. Sortomme, S. S. Venkata, and J. Mitra, "Microgrid protection using communication-assisted digital relays," IEEE Trans. Power Deliv., vol. 25, no. 4, pp. 2789-2796, 2010.

[58] M. Dewadasa, "Protection of microgrids using differential relays," 21th Aus. Univ. Power Eng. Conf. (AUPEC), Brisbane, Australia, pp. 1-6, 2011.

[59] H. Nikkhajoei, and R. H. Lasseter, "Microgrid fault protection based on symmetrical and differential current components," Consortium for Electric Reliability Technology Solutions, Contract No. 500-03$024,2006$.

[60] M. A. Zamani, T. S. Sidhu, and A. Yazdani, “A protection strategy and microprocessor-based relay for low-voltage microgrids," IEEE Trans. Power Deliv., vol. 26, no. 3, pp. 1873-1883, 2011.

[61] S. Mirsaeidi, D. Mat Said, M. W. Mustafa, and M. Hafiz Habibuddin, “A protection strategy for microgrids based on positive-sequence component," IET Renew. Power Gener., vol. 9, no. 6, pp. 600-609, 2015.

[62] A. R. Singh, and S. S. Dambhare, "Adaptive distance protection of transmission line in presence of SVC,” Int. J. Electr. Power Energy Syst., vol. 53, no. 1, pp. 78-84, 2013.

[63] B. J. Brearley, and R. R. Prabu, "A review on issues and approaches for microgrid protection," Renew. Sustain. Energy Rev., vol. 67, pp. 988-997, 2017.

[64] M. Dewadasa, "Protection for distributed generation interfaced networks," Ph.D. thesis, Faculty of Built Environment and Engineering, Queensland University of Technology, 2010. 
This article has been accepted for publication in a future issue of this journal, but has not been fully edited. Content may change prior to final publication in an issue of the journal. To cite the paper please use the doi provided on the Digital Library page.

[65] M. Dewadasa, R. Majumder, A. Ghosh, and G. Ledwich, "Control and protection of a microgrid with converter interfaced micro sources,” in 2009 International Conference on Power Systems, Kharagpur, India, pp. 1-6, 2009.

[66] S. Kar, and S. R. Samantaray, "Time-frequency transform-based differential scheme for microgrid protection," IET Gener. Transm. Distrib., vol. 8, no. 2, pp. 310-320, 2014.

[67] H. Al-Nasseri, and M. A. Redfern, "Harmonics content based protection scheme for Micro-grids dominated by solid state converters," 12th International Middle-East Power System Conference, Aswan, Egypt, pp. 50-56, 2008.

[68] M. Petit, X. L. Pivert. and L. G. Santander, "Directional relays without voltage sensors for distribution networks with distributed generation: Use of symmetrical components," Electr. Power. Syst. Res, vol. 80, pp. 1222-1228, 2010.

[69] Z. Chen, X. Pei, and L. Peng, "Harmonic components based protection strategy for inverter-interfaced AC microgrid," IEEE Energy Conversion Congress and Exposition (ECCE), Milwaukee, WI, pp. 1-6, 2016.

[70] S. A. Saleh, R. Ahshan, M. A. Rahman, M. S. Abu Khaizaran, and B. Alsayed, "Implementing and testing d-q WPT-based digital protection for micro-grid systems," IEEE Industry Applications Society Annual Meeting, Orlando, FL, pp. 1-8, 2011.

[71] D. P. Mishra, S. R. Samantaray, and G. Joos, “A Combined Wavelet and Data-Mining Based Intelligent Protection Scheme for Microgrid,” in IEEE Trans. Smart Grid, vol. 7, no. 5, pp. 2295-2304, 2016.

[72] S. Kar and S. R. Samantaray, "High impedance fault detection in microgrid using maximal overlapping discrete wavelet transform and decision tree," International Conference on Electrical Power and Energy Systems (ICEPES), Bhopal, India, pp. 258-263, 2016.

[73] P. Kanakasabapathy, and M. Mohan, "Digital protection scheme for microgrids using wavelet transform," IEEE International Conference on Electron Devices and Solid-State Circuits (EDSSC), Singapore, pp. 664-667, 2015.

[74] S. Shi, B. Jiang, X. Dong and Z. Bo, "Protection of microgrid," 10th IET International Conference on Developments in Power System Protection (DPSP 2010), Manchester, UK, pp. 1-4, 2010.

[75] X. Li, A. Dyśko, and G. Burt, "Enhanced protection for inverter dominated microgrid using transient 
This article has been accepted for publication in a future issue of this journal, but has not been fully edited.

Content may change prior to final publication in an issue of the journal. To cite the paper please use the doi provided on the Digital Library page.

fault information," 11th IET International Conference on Developments in Power Systems Protection (DPSP 2012), Birmingham, UK, pp. 1-5, 2012.

[76] X. Li, A. Dyśko, and G. M. Burt, “Traveling Wave-Based Protection Scheme for Inverter-Dominated Microgrid Using Mathematical Morphology," in IEEE Trans. Smart Grid, vol. 5, no. 5, pp. 2211-2218, 2014.

[77] C. H. Lee, and C. J. Lu, “Assessment of grounding schemes on rail potential and stray currents in a DC transit system," IEEE Trans. Power Deliv., vol. 21, no. 4, pp. 1941-1947, 2006.

[78] L. Tang, and B. T. Ooi, "Locating and isolating DC faults in multi-terminal DC systems," IEEE Trans. Power Deliv., vol. 22, no. 3, pp. 1877-1884, 2007.

[79] J. G. Ciezki, and R. W. Ashton, "Selection and stability issues associated with a navy shipboard DC Zonal Electric Distribution System,” IEEE Trans. Power Deliv., vol. 15, no. 2, pp. 665-669, 2000.

[80] C. Meyer, S. Schroder, and R. W. De Doncker, "Solid-state circuit breakers and current limiters for medium-voltage systems having distributed power systems," IEEE Trans. Power Electron., vol. 19, no. 5, pp. 1333-1340, 2004.

[81] D. Lawes, "Design of a Solid-State DC Circuit Breaker for Light Rail Transit Power Supply Network," 2014 IEEE Energy Conversion Congress and Exposition (ECCE), Pittsburgh, PA, U.S., pp. 350-357, 2014.

[82] M. E. Baran, and N. R. Mahajan, "Overcurrent protection on voltage-source-converter-based multiterminal DC distribution systems," IEEE Trans. Power Deliv., vol. 22, no. 1, pp. 406-412, 2007.

[83] D. Salomonsson, L. Söder, and A. Sannino, "Protection of low-voltage DC microgrids," IEEE Trans. Power Deliv., vol. 24, no. 3, pp. 1045-1053, 2009.

[84] K. A. Corzine, and R. W. Ashton, “A new Z-source DC circuit breaker,” IEEE Trans. Power Electron., vol. 27, no. 6, pp. 2796-2804, 2012.

[85] S. D. A. Fletcher, P. J. Norman, S. J. Galloway, P. Crolla, and G. M. Burt, "Optimizing the roles of unit and non-unit protection methods within DC microgrids," IEEE Trans. Smart Grid, vol. 3, no. 4, pp. 2079-2087, 2012.

[86] S. S. Khan, Modeling and operating strategies of microgrids for renewable energy communities. Peshawar, Pakistan: IQRA National University Peshawar, pp.735-760, 2017. 
This article has been accepted for publication in a future issue of this journal, but has not been fully edited.

Content may change prior to final publication in an issue of the journal. To cite the paper please use the doi provided on the Digital Library page.

[87] B. Al-Omar, and A. Al-Ali, "Role of information and communication technologies in the smart grid," Journal of Emerging Trends in Computing and Information Sciences, vol. 3, no. 5, pp. 707-716, 2012.

[88] L. K. Siow, P. L. So, H. B. Gooi, F. L. Luo, C. J. Gajanayake, and Q. N. Vo, "Wi-Fi based server in microgrid energy management system," TENCON 2009 - 2009 IEEE Region 10 Conference, Singapore, Singapore, pp. 1-5, 2009.

[89] A. P. S. Meliopoulos, G. Cokkinides, R. Huang, E. Farantatos, S. Choi, Y. Lee, and X. Yu, "Smart grid technologies for autonomous operation and control," IEEE Trans. Smart Grid, vol. 2, no. 1, pp. 1-10, 2011.

[90] A. Gopalakrishnan, and A. C. Biswal, "Applications of emerging communication trends in automation," 2016 IEEE 6th International Conference on Power Systems (ICPS), New Delhi, India, pp. 2-7, 2016.

[91] M. Erol-Kantarci, and H. T. Mouftah, "Energy-Efficient Information and Communication Infrastructures in the Smart Grid: A Survey on Interactions and Open Issues," in IEEE Communications Surveys \& Tutorials, vol. 17, no. 1, pp. 179-197, 2015.

[92] S. Beheshtaein, M. Savaghebi, J. C. Vasquez, S. Member, and J. M. Guerrero, "Protection of AC and DC Microgrids : Challenges, Solutions and Future Trends," IECON 2015 - 41st Annual Conference of the IEEE Industrial Electronics Society, Yokohama, Japan, pp. 5253-5260, 2015.

[93] S. A. Hosseini, H. A. Abyaneh, S. H. H. Sadeghi, F. Razavi, and A. Nasiri, “An overview of microgrid protection methods and the factors involved," Renew. Sustain. Energy Rev., vol. 64, pp. 174-186, 2016. 